\section{Effects of Flowering and Foliage Plants in Hospital Rooms on Patients Recovering from Abdominal Surgery}

\author{
Seong-Hyun Park ${ }^{1}$ and Richard H. Mattson
}

ADDITIONAL INDEX WORDS. appendectomy surgical recovery, horticultural therapy, hospital plant environments, human issues in horticulture, people-plant interaction

\begin{abstract}
SUMMARY. Using various medical and psychological measurements, this study performed a randomized clinical trial with surgical patients to evaluate if plants in hospital rooms have therapeutic influences. Ninety patients recovering from an appendectomy were randomly assigned to hospital rooms with or without plants. Patients in the plant treatment room viewed eight species of foliage and flowering plants during their postoperative recovery periods. Data collected for each patient included length of hospitalization, analgesics used for postoperative pain control, vital signs, ratings of pain intensity, pain distress, anxiety, and fatigue, the StateTrait Anxiety Inventory Form Y-1, the Environmental Assessment Scale, and the Patient's Room Satisfaction Questionnaire. Patients in hospital rooms with plants and flowers had significantly fewer intakes of postoperative analgesics, more positive physiological responses evidenced by lower systolic blood pressure and heart rate, lower ratings of pain, anxiety, and fatigue, and more positive feelings and higher satisfaction about their rooms when compared with patients in the control group. Findings of this research suggested that plants in a hospital environment could be noninvasive, inexpensive, and an effective complementary medicine for patients recovering from abdominal surgery.
\end{abstract}

A ppendectomy is an acute surgery characterized by localized abdominal pain requiring a relatively short hospitalization of up to $5 \mathrm{~d}$. This is a comparatively standardized medical procedure with similar postoperative management in the uncomplicated cases. Appendectomy surgery, however, may create multiple stressors to patients, including pain and physical discomfort, fear of medical procedures, isolation from family and friends, and lack of familiarity with medical personnel, hospital equipment, and environment. Numerous studies suggest that when patients have greater stress associated with surgery, they typically experience more severe postoperative pain and a slower and more complicated postoperative recovery (Cohen and Williamson, 1991; Johnston, 1988; Johnston and Wallace, 1990). Some of the postoperative problems related to stress can be mediated through intakes of

$\overline{\text { Department of Horticulture, Forestry and Recreation }}$ Resources, Kansas State University, Manhattan, KS 66506

We thank Hae-Chang Cho and the medical staff for valuable assistance with this project, and James Higgins at Kansas State University for statistical advice.

${ }^{1}$ Corresponding author. E-mail: hyunipark@gmail.com. anesthetics and analgesics. However, these drugs have side effects that can produce postoperative physiological problems (e.g., vomiting, headaches, nausea, and pain at the incision site), drug dependency, and even be fatal if not properly administered (Abbott and Abbott, 1995; Coniam and Diamond, 1994). Therefore, it would be useful to develop nonpharmacologic approaches to improving the patient experiences with pain and stress during hospitalization.

To promote the speed of postoperative recovery and to improve the quality of life during hospitalizations, it is important to provide patients with not only the best treatment possible, but also to remove such sources of stress and to counter them with positive distractions that have soothing and stress-reducing effects. Viewing nature or having plants present has been considered an effective positive distraction that may provide ample involuntary attention, increase positive feelings, block or reduce worrisome thoughts, and promote restoration from stress (Ulrich, 1992). Researchers who have assessed the impact of nature/plants on human health have suggested that people-plant interactions provide physiological stress reduction (Chang and Chen, 2005; Coleman and Mattson, 1995; Lohr et al., 1996; Ulrich et al., 1991; Verderber and Reuman, 1987). This relaxation occurs remarkably quickly, almost within minutes (Ulrich and Simons, 1986). People in a natural/plant environment not only showed faster physical recovery from stress, but also improved psychological (Kaplan, 2001; Kaplan and Kaplan, 1995; Ulrich, 1979), emotional (Adachi et al., 2000; Ulrich, 1981; Ulrich et al., 1991), and cognitive health (Cimprich, 1993; Hartig et al., 1991; Tennessen and Cimprich, 1995). In addition, viewing nature/ plants is linked to positive health outcomes of individuals, such as in pain reduction, less need for analgesics, and a quicker recovery from surgery (Diette et al., 2003; Lohr and Pearson-Mims, 2000; Park et al., 2004; Ulrich, 1984).

Clinical trials studying the health benefits of viewing indoor plants on stress and recovery of surgical patients within a hospital setting do not exist. This investigation used various medical and psychological measurements to determine if plants in hospital rooms had therapeutic influences on the health outcomes of appendectomy patients.

\section{Materials and methods}

Subjects. The sample consisted exclusively of patients who had undergone appendectomy surgery. Ninety patients $(52$ males and 38 females, mean age $=37.6 \pm 9.41$ years, ranging from 21 to 60 years) were studied from July 2005 to Jan. 2006 in a 250-bed suburban hospital in Korea. Human research protocols for this study were approved by the

\begin{tabular}{llll}
\hline $\begin{array}{l}\text { Units } \\
\begin{array}{l}\text { To convert U.S. to SI, } \\
\text { multiply by }\end{array}\end{array}$ & U.S unit & SI unit & $\begin{array}{l}\text { To convert SI to U.S., } \\
\text { multiply by }\end{array}$ \\
\hline 0.1333 & $\mathrm{~mm} \mathrm{Hg}$ & $\mathrm{kPa}$ & 7.5006 \\
28,350 & $\mathrm{oz}$ & $\mathrm{mg}$ & $3.5274 \times 10^{-5}$ \\
$\left({ }^{\circ} \mathrm{F}-32\right) \div 1.8$ & ${ }^{\circ} \mathrm{F}$ & ${ }^{\circ} \mathrm{C}$ & $\left(1.8 \times{ }^{\circ} \mathrm{C}\right)+32$
\end{tabular}

\footnotetext{
Hartednology October-December 2008 18(4)
} 
institution review boards of both the academic and hospital setting. Patients were informed that their medical history and current medical records would be reviewed and each signed an informed consent form. Patients were randomly assigned to control or plant rooms (Fig. 1) as they became available. Ten rooms, which were located on the same floor and the same side of the building, were identical except for the presence or absence of plants. Patient views from the hospital windows were only of the sky with no presence of trees or other buildings. Patients in the plant group were allowed to view plants during their recovery periods after surgery until discharge. Excluded from the study were 65 patients who were younger than 19 years or older than 60 years, and those who reported chronic (e.g., diabetes or high blood pressure) or current acute (e.g., upper respiratory infection) health problems, a history of psychiatric problems (e.g., depression or anxiety), or uncorrected hearing or visual impairments. All were in good health before diagnosis of surgical treatment.

Measurements. Medical and psychological data were collected from each patient. This included length of hospitalization, analgesics used for postoperative pain control, vital signs, ratings of pain intensity, pain distress, anxiety and fatigue (PPAF), the State-Trait Anxiety Inventory Form Y-1 (STAI-Yl), Environmental Assessment Scale (EAS), and the Patient's Room Satisfaction Questionnaire (PRSQ).
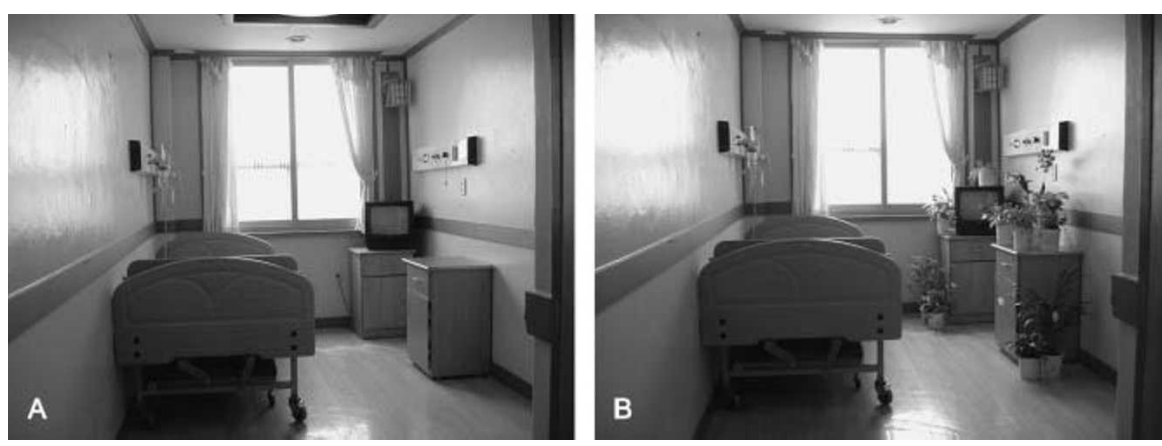

Fig. 1. Photographs of the two hospital room treatments. (A) No plants and (B) foliage and flowering plants. The rooms, which were located on the same floor and the same side of the building, were identical except for the presence or absence of plants. The combinations of plants used in each room were identical. Room $B$ contained single plants of arrowhead vine, cretan brake fern, variegated vinca, and yellow star jasmine, arranged with two plants each of dendrobium, peace lily, golden pothos, and kentia palm.

Outcome data of length of hospitalization, postoperative analgesic intakes, and vital signs were extracted from patient charts. Length of hospitalization was defined as days from surgery to discharge. Postoperative analgesics were classified as weak, moderate, or strong on the basis of the drug and amount, and whether it was narcotic or not. The weak category was dominated by small amounts of diclofenac sodium injections up to $75 \mathrm{mg} \cdot \mathrm{d}^{-1}$, a nonsteroidal anti-inflammatory drug (NSAID), and the moderate category included large amounts of diclofenac sodium injections up to $150 \mathrm{mg} \cdot \mathrm{d}^{-1}$. In the strong category, pethidine hydrochloride injections (narcotic analgesics) were used. Vital signs recorded were systolic and diastolic blood pressures (millimeters of mercury), body temperature $\left({ }^{\circ} \mathrm{C}\right)$, heart rate (beats per minute), and respiratory rates (breaths per minute). Vital signs were defined as the average of three readings taken per day. All measurements were taken using standard, noninvasive technology and were recorded on patient charts.

Levels of the PPAF were measured using a 101-point numerical rating scale (NRS-101). The validity of the NRS-101 and its sensitivity to treatment effects have been well documented (Jensen and Karoly, 1992; Jensen et al., 1986). The NRS-101 (rating from 1 to 100 ) is reported to have several advantages over the other rating scales and to be more sensitive to treatment effect than the NRS-11 (rating from 1 to
10) due to a large number of response categories (Jensen et al., 1986).

The STAI-Y (Spielberger, 1983) is comprised of a self-report measurement of anxiety and has been used extensively in research and clinical practice. The STAI consists of two scales. The STAI-Yl scale includes 20 statements intended to measure transitory feelings of tension, nervousness, apprehension, and worry, whereas the STAI-Y2 section evaluates the stable personality trait of anxiety proneness. This study used the STAI-Yl because it was designed to measure changes in anxiety resulting from situational stress. Psychometric properties of the STAI-Y and studies supporting its construct validity are presented in the STAI-Y manual (Spielberger, 1983).

To measure patients' feelings in response to their hospital rooms, the modified EAS was used (Rohles and Milliken, 1981). The EAS consists of 13 adjective pair semantic differential scales. The EAS has been used in previous studies to evaluate the affective characteristics of the environment and various features it contains (Laviana, 1985; Laviana et al., 1983).

To assess patient satisfaction with the hospital room, patients were asked to complete the PRSQ, which indicated three positive and three negative qualities of their room environments. Patients were further asked their willingness to return to their room in any future hospitalization. Space was provided so that patients could add comments.

Procedures. A meeting with the hospital doctors and nurses was held before the beginning of the research. Research objectives were explained that included their need to treat patients similarly. In addition, nurses were assigned to help patients in the control and plant rooms and were urged not to be influenced by the content of the rooms. After obtaining the informed consent agreement from the patients and after health screening, measurements of the PPAF, STAI-Yl, and EAS were administered in the hospital room. For the plant treatment, 12 potted foliage and flowering plants with sterile, soilless potting mix were placed in the hospital room after patients left the room for surgery. Plants selected for the hospital rooms were dendrobium (Dendrobium phalaenopsis), 
peace lily (Spathiphyllum 'Starlight'), golden pothos (Epipremnum aureum), kentia palm (Howea forsteriana), arrowhead vine (Syngonium podophyllum 'Albolineatum'), cretan brake fern (Pteris cretica 'Albolineata'), variegated vinca (Vinca minor 'Illumination'), and yellow star jasmine (Trachelospermum asiaticum 'Ougonnishiki'). Single plants of four species were arranged with two plants each of dendrobium, peace lily, golden pothos, and kentia palm. Hospital rooms had large windows with natural sunlight during the daytime unless the shades were drawn. From July through December, although the length of the natural photoperiod declined, the photoperiod was similar throughout the study with interior room lighting. Consistent temperature and humidity for patient comfort level were similar to those required by the plants selected. Plant selection was based on space consideration, sunlight accessibility, requirements of temperature and humidity, low maintenance, and visual appeal with various colors, sizes, patterns, and shapes. Plants were added or removed as needed to accomplish each treatment. The combinations of plants used in each room were identical. Plants were grown in self-watering containers, and patients were not disturbed by plant maintenance during hospitalizations. Patients were not told of the study objectives or how to interact with the plants. Control rooms contained no plant materials. During the first 3 days after surgery, the PPAF and STAI-Yl were administered at midmorning. The second trial of the EAS and the initial trial of the PRSQ were administered on the last day of hospitalizations. All measurements were taken by the researcher except demographics, analgesic intake, and vital signs, which were recorded by medical staff.

Data analyses. Analysis of covariance (ANCOVA) (Littell et al., 2006) using SAS PROC GLM (version 8.0; SAS Institute, Cary, NC) was completed for data of hospitalization and the EAS to test for differences between groups. Age was used as the covariate for ANCOVA. A repeated-measures ANCOVA (Littell et al., 2006) using SAS PROC MIXED was done for data of vital signs, the PPAF, and the STAI-YI to test for differences between groups at each day of hospitalization and to compare trends for groups over postoperative recovery periods. Because of the differences in age and preoperative score, the patient's age and preoperative score were used as the covariates for a repeated-measures (Higgins, 2004) using SAS PROC FREQ was performed for analgesic intake to test for differences between groups at each day of postoperative recovery periods. Alpha level was set at 0.05 .

\section{Results and discussion}

The mean length of hospitalizations for the plant group was $4.64 \mathrm{~d}$ and was not significantly different from that of the control group at 4.88 d. Analgesic intake (Fig. 2) was significantly different for the plant group compared with the control group at the third day after surgery $(P=0.041)$. Patients exposed to plants were less frequently given weak and moderate analgesics compared with patients in the control group.

A repeated-measures ANCOVA performed for systolic blood pressure ANCOVA. The exact chi-square test

and heart rate data demonstrated a significant day-by-group interaction ( $P=0.047, P=0.048$, respectively). At the day of surgery and the first day after surgery, there were significant differences in systolic blood pressure $(P=0.04, P=0.04$, respectively $)$ and heart rate $(P=0.01, P=0.03$, respectively), which were significantly lower with the plant group compared with the control group (Fig. 3). No significant day-by-group interactions and no significant group differences were noted regarding diastolic blood pressure, temperature, and respiratory rate during the recovery periods.

As shown in Table 1 , the means are presented for preoperative and postoperative ratings of the PPAF and the STAI-Yl. Among the PPAF outcomes, significant day-by-group interactions were found for self-rated pain intensity, pain distress, and fatigue $(P=0.03, P=0.047, P=$ 0.04 , respectively). Levels of pain intensity, pain distress, and fatigue remarkably decreased for most patients in both groups through the recovery periods. Self-rated pain intensity and pain distress were

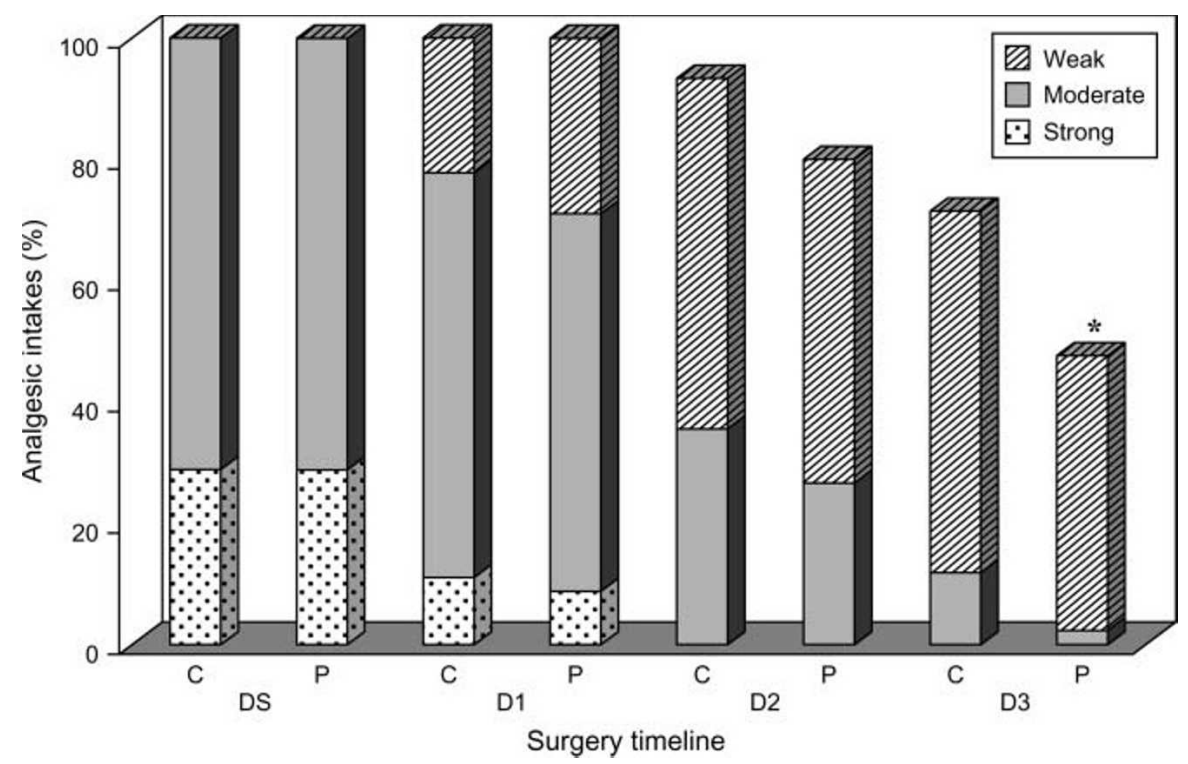

Fig. 2. Comparisons of control (C) and plant (P) groups (45 appendectomy patients per group) in postoperative analgesic intakes. Analgesics were classified as weak, moderate, or strong on the basis of the drug and amount, and whether it was narcotic. The weak category was dominated by small amounts of diclofenac sodium (a nonsteroidal anti-inflammatory drug) injections up to $75 \mathrm{mg} \cdot \mathrm{d}^{-1}$ $\left(1 \mathrm{mg}=3.5274 \times 10^{-5} \mathrm{oz}\right)$ and the moderate category included large amounts of diclofenac sodium injections up to $150 \mathrm{mg} \cdot \mathrm{d}^{-1}$. In the strong category, pethidine hydrochloride (a narcotic analgesic) injections were used. DS, D1, D2, and D3 indicate the day of surgery, first day after surgery, second day after surgery, and third day after surgery, respectively. Some of the patients did not receive analgesics on D2 and D3, and a few had left the hospital on D3. An asterisk indicates significance at $P<0.05$ (compared with control). 

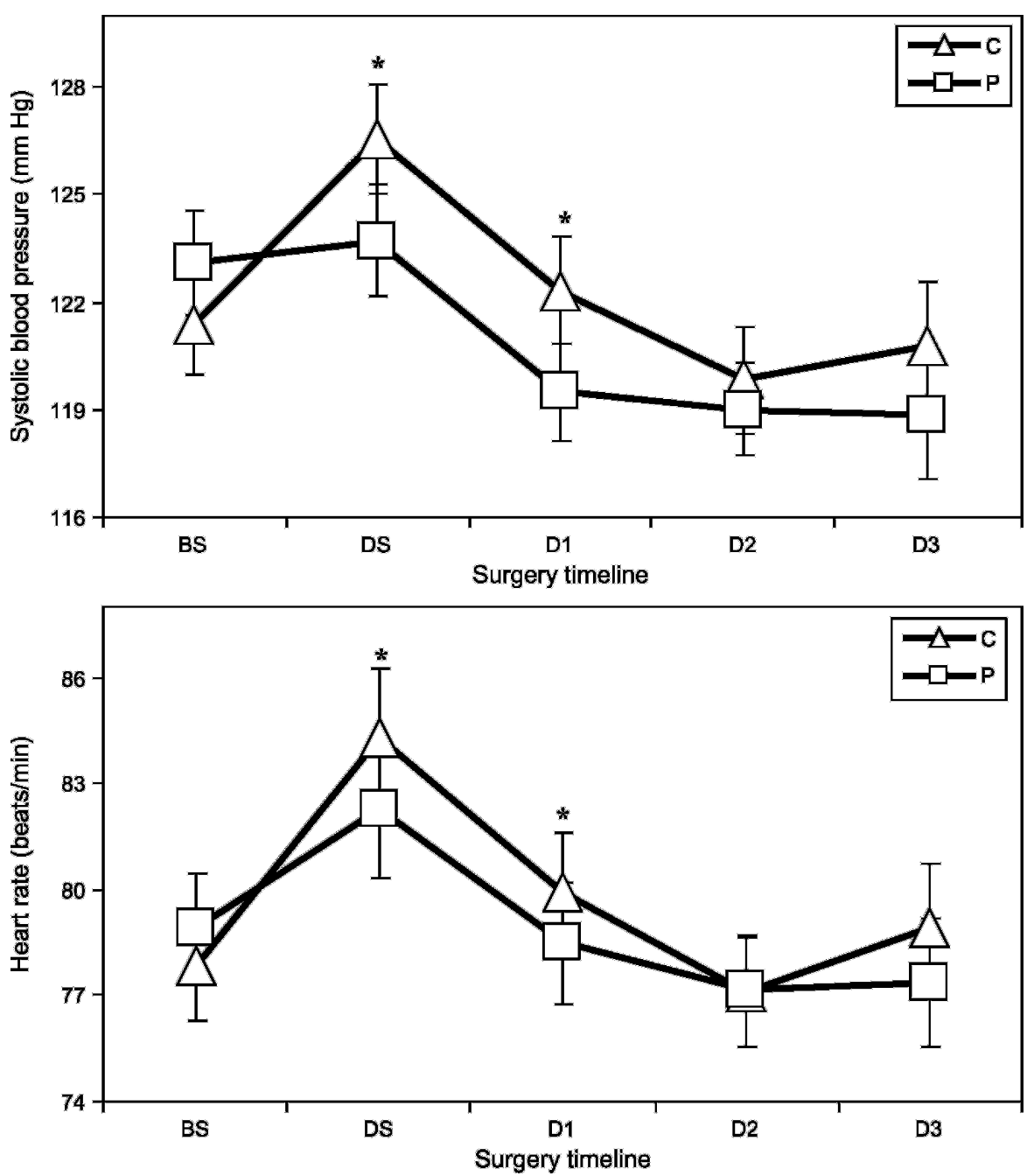

Fig. 3. Comparisons of control $(C)$ and plant $(P)$ groups (45 appendectomy patients per group) in systolic blood pressure and heart rate. Error bars label sE of estimates. BS, DS, D1, D2, and D3 indicate before surgery, the day of surgery, first day after surgery, second day after surgery, and third day after surgery, respectively. Note that BS (preoperative scores) used as the covariates. Means at DS, D1, D2, and D3 for systolic blood pressure and heart rate are adjusted for differences from BS. An asterisk indicates control versus plant at $P<0.05(1 \mathrm{~mm} \mathrm{Hg}=0.1333 \mathrm{kPa})$. significantly lower for those patients exposed to plants compared with no plants on the third day after surgery $(P=0.01, P=0.01$, respectively $)$. The dynamic changes of pain distress were parallel with that of pain intensity and were consistently lower than the pain intensity ratings. Comparing plant group patients to control group patients, self-rated fatigue was significantly lower on the third day after surgery $(P=0.03)$. Levels of anxiety and the STAI-Yl were highest before surgery and were remarkably decreased for most patients in both groups during the recovery periods. No significant day-by-group interactions were reported, and significant group differences were found for selfrated anxiety and the STAI-YI. Patients in the plant group were characterized by significantly lower levels of anxiety and tension than patients in the control group during the recovery periods $(P=0.01, P=0.02$, respectively).

Significant differences between the EAS responses of the two groups were found for the seven items (Table 2 ). The EAS responses to plants indicated that patients during the recovery periods felt their rooms more satisfying, relaxing, comfortable, colorful, pleasant smelling, calming, and attractive compared with those in the control rooms.

Results of the PRSQ showed the majority of patients in the plant group indicated that plants were the most positive qualities of their rooms (93\%), whereas patients in the control group reported watching television as the most favorable aspect of their rooms $(91 \%)$. The next categories of positive qualities regarding the

Table 1. Pain intensity, pain distress, anxiety, and fatigue (PPAF) ${ }^{\mathrm{z}}$ and State-Trait Anxiety Inventory Form Y-1 (STAI-Y1) ${ }^{\mathrm{y}}$ mean ratings for control $(C)$ and plant $(P)$ groups of 45 appendectomy patients per group.

\begin{tabular}{|c|c|c|c|c|c|c|c|c|c|c|}
\hline \multirow[b]{2}{*}{ Timeline $^{\mathrm{x}}$} & \multicolumn{2}{|c|}{$\begin{array}{l}\text { Pain intensity }^{z} \\
(0-100 \text { scale })\end{array}$} & \multicolumn{2}{|c|}{$\begin{array}{l}\text { Pain distress } \\
(0-100 \text { scale })\end{array}$} & \multicolumn{2}{|c|}{$\begin{array}{c}\text { Anxiety } \\
(0-100 \text { scale })\end{array}$} & \multicolumn{2}{|c|}{$\begin{array}{c}\text { Fatigue }^{\mathrm{z}} \\
(0-100 \text { scale })\end{array}$} & \multicolumn{2}{|c|}{$\begin{array}{l}\text { STAI-Y1 }^{y} \\
(1-4 \text { scale })\end{array}$} \\
\hline & $\mathrm{C}$ & $\mathbf{P}$ & $\mathrm{C}$ & $\mathbf{P}$ & $\mathrm{C}$ & $\mathbf{P}$ & $\mathrm{C}$ & $\mathbf{P}$ & $\mathrm{C}$ & $\mathbf{P}$ \\
\hline $\mathrm{BS}^{\mathrm{w}}$ & 66.44 & 69.02 & 65.20 & 67.96 & 74.68 & 76.89 & 48.79 & 45.58 & 49.04 & 50.84 \\
\hline Dl & 87.89 & 87.71 & 86.43 & 85.55 & 48.93 & $46.57^{*}$ & 77.42 & 77.06 & 43.61 & $41.36^{*}$ \\
\hline D2 & 77.00 & 72.93 & 69.19 & 65.66 & 31.93 & $29.57^{*}$ & 54.42 & 53.73 & 34.90 & 32.89 * \\
\hline D3 & 58.42 & $52.70 *$ & 54.21 & $48.78 *$ & 17.04 & $15.32 *$ & 28.26 & 22.41 * & 29.51 & $28.35^{*}$ \\
\hline
\end{tabular}

${ }^{2}$ PPAF is based on a 101 -point numerical rating scale (pain intensity: $0=$ no pain, $100=$ pain as bad as it could be; pain distress: $0=$ comfortable, $100=$ excruciating; anxiety: $0=$ complete relaxation, $100=$ the worst feelings of anxiety; fatigue: $0=$ no fatigue, $100=$ worst fatigue) .

yTwenty items ( 10 anxiety-present items and 10 anxiety-absent items) were given a weighted score of 1 to $4(1=$ not at all, $2=$ somewhat, $3=$ moderately, $4=$ very much). A rating of 4 indicates the presence of a high level of anxiety for 10 anxiety-present items and the anxiety-absent items for which the scoring weights are reversed. Scores are ranging from 20 to 80 . A lower value indicates less anxiety.

${ }^{\mathrm{x}} \mathrm{BS}=$ before surgery; $\mathrm{D} 1$ = first day after surgery; $\mathrm{D} 2=$ second day after surgery; $\mathrm{D} 3=$ third day after surgery.

"BS (preoperative scores) used as the covariates. Means at D1, D2, and D3 for the PPAF and the STAI-Y1 are adjusted for differences from BS.

${ }^{*} P<0.05$ (compared with control) 
Table 2. Mean changes in the 13 items of the Environmental Assessment Scale (EAS; Rohles and Milliken, 1981) self-rated by patients with appendectomy (45 patients per group) before surgery and at the last day of hospitalization, in responses to viewing "foliage and flowering plants" and "no plants" during recovery.

\begin{tabular}{|c|c|c|c|c|c|c|}
\hline \multirow[b]{3}{*}{ EAS items } & \multicolumn{3}{|c|}{ Control group } & \multicolumn{3}{|c|}{ Plants group } \\
\hline & Pre & Post & Post-Pre $^{\mathrm{z}}$ & Pre & Post & Post-Pre \\
\hline & \multicolumn{6}{|c|}{$(1-9 \text { scale })^{\mathrm{y}}$} \\
\hline Clean-dirty & 6.42 & 6.18 & -0.24 & 5.88 & 5.81 & -0.07 \\
\hline Relaxing-stressing & 5.65 & 5.48 & -0.17 & 5.83 & 6.53 & $0.70 * *$ \\
\hline Comfortable-uncomfortable & 5.74 & 5.61 & -0.13 & 5.86 & 6.46 & $0.60 * *$ \\
\hline Pleasant smell-unpleasant smell & 4.59 & 4.54 & -0.05 & 4.79 & 5.15 & $0.36^{*}$ \\
\hline Bright-dull & 7.30 & 7.39 & 0.09 & 7.05 & 7.13 & 0.08 \\
\hline Spacious-crowded & 6.07 & 5.98 & -0.09 & 5.90 & 5.69 & -0.21 \\
\hline Calming-irritating & 5.88 & 5.70 & -0.18 & 5.90 & 6.44 & $0.54^{*}$ \\
\hline Warm-cool & 5.00 & 5.11 & 0.11 & 5.01 & 5.04 & 0.03 \\
\hline
\end{tabular}

${ }^{2}$ Differences in EAS scores of pretest (self-rated before surgery) and posttest (self-rated at the last day of hospitalization), were computed.

${ }^{\mathrm{y}} \mathrm{l}=$ least desirable, $9=$ most desirable.

${ }^{*}$ and ${ }^{* *}$ indicate significance at $P<0.05$ or 0.01 , respectively (compared with control).

hospital room included appropriate temperature $(77 \%)$, television $(66 \%)$, and sunshine $(44 \%)$ for the plant group, whereas appropriate temperature $(71 \%)$, sunshine $(44 \%)$, and quietness (11\%) were highly favored for the control group. Regarding negative qualities of hospital room, patients in the control and plant groups had similar negative comments concerning toilet facilities, insufficient space, and the hospital environments. Patients were further asked about their willingness to return to their room in any future hospitalization. Ninety-one percent of patients in the plant group responded positively, whereas $71 \%$ of patients in the control group reported a willingness to return.

Voluntary comments of patients were collected from nurses and from the PRSQ. Many patients in the plant group stated that plants helped them relax or feel less anxious. Plants were associated with positive memories, and some patients believed that plants had diminished their pain. Furthermore, the presence of plants in the hospital room promoted a positive image of the hospital as a healing environment and a place designed to be sensitive to patient needs. As patients recovered from surgery and regained mobility, nursing and medical staff reported increased interaction with plants. This included watering plants, removing dead leaves, touching them, and moving them for a better view or close to window for better sunlight.

Unlike cut flowers, potted foliage and flowering plants are likely to remain for long periods of time. During the 7 months of the study period, seven species of plants maintained their qualities, and only the dendrobium needed to be replaced due to flower deterioration.

A number of studies have shown that indoor plants make air healthier and provide an optimum indoor environment. The presence of plants reduced sick-building syndrome by removing pollutants (Darlington et al., 2001; Nishida et al., 1991; Wolverton et al., 1989; Wood et al., 2002 ), increased relative humidity up to human comfort level (Lohr, 1992; Wolverton and Wolverton, 1993), and improved indoor air quality by reducing the quantity of mold spores and airborne microorganisms (Wolverton and Wolverton, 1993).

Previous research (Park et al., 2004) in a simulated hospital room indicated that pain sensitivity and perception were significantly decreased when foliage and flowering plants were present compared with just foliage or a room without any plants or flowers. A study of patients recovering from abdominal surgery found that individuals had shorter hospital stays, fewer negative comments in nurses' notes, and fewer intakes of analgesics if their bedside windows overlooked trees rather than a brick wall (Ulrich, 1984). This study extends earlier studies documenting the health benefits of passively viewing plants.

The findings of this study confirmed that introducing plants and flowers into a hospital room during the recovery period had a positive influence linking directly to health outcomes of surgical patients. Patients exposed to plants had significantly less need for analgesics, enhanced physiological responses, lower ratings of pain, anxiety, and fatigue, and more positive feelings and higher satisfaction about their hospital rooms compared with patients without plants.

Colorful fresh cut flowers and blooming or green plants could be a complementary medicine for patients. If properly maintained, indoor plants can provide a great opportunity for patients to experience nature in all seasons when outdoor scenery cannot provide this benefit. Furthermore, they can provide meaningful therapeutic contact especially for patients spending much of their time indoors while recovering from painful surgery.

Findings from this study may not be applied to the immediate environments of severely immunocompromised and intensive care unit patients. However, this study provides strong evidence that contact with plants is 
directly beneficial to patients' health. This nonpharmacological complementary approach is medically beneficial and clearly cost effective not only to patients, but also to health insurance companies by reducing the costs of hospitalization and analgesic consumption. Further research will support hospital administrator and medical doctor decisions to use plants as a healing modality.

\section{Literature cited}

Abbott, J. and P. Abbott. 1995. Psychological and cardiovascular predictors of anesthesia induction, operative and postoperative complications in minor gynecological surgery. Br. J. Clin. Psychol. 34: 613-625.

Adachi, M., C.L.E. Rode, and A.D. Kendle. 2000. Effects of floral and foliage displays on human emotions. HortTechnology 10(1):59-63.

Chang, C. and P. Chen. 2005. Human response to window views and indoor plants in the workplace. HortScience 40(5):1354-1359.

Cimprich, B. 1993. Development of an intervention to restore attention in cancer patients. Cancer Nurs. 16(2):83-92.

Cohen, S. and G. Williamson. 1991. Stress and infectious disease in humans. Psychological Bul. 109:5-24.

Coleman, C.K. and R.H. Mattson. 1995. Influences of foliage plants of human stress during thermal biofeedback training. HortTechnology 5(2):137-140.

Coniam, S.W. and A.W. Diamond. 1994. Practical pain management. Oxford Univ. Press, Oxford, UK.

Darlington, A.B., J.F. Dat, and M.A. Dixon. 2001. The biofiltration of indoor air: Air flux and temperature influences the removal of toluene, ethylbenzene, and xylene. Environ. Sci. Technol. 35(1):240246.

Diette, G., E. Haponik, and H. Rubin. 2003. Distraction therapy with nature sights and sounds reduces pain during flexible bronchoscopy. Chest 12(3):941-948.

Hartig, T.A., M. Mang, and G.W. Evans. 1991. Restorative effects of natural environment experiences. Environ. Behav. $23(1): 3-27$.

Higgins, J.J. 2004. Introduction to modern nonparametric statistics. Brooks/ Cole, Pacific Grove, CA.
Jensen, M.P. and P. Karoly. 1992. Selfreport scales and procedures for assessing pain in adults, p. 193-213. In: D.C. Turk and R. Melzack (eds.). Handbook of pain assessment. Guilford Press, New York.

Jensen, M.P., P. Karoly, and S. Braver. 1986. The measurement of clinical pain intensity: A comparison of six methods. Pain 27:117-126.

Johnston, M. 1988. Impending surgery, p. 79-100. In: S. Fisher and J. Reason (eds.). Handbook of life stress, cognition and health. Wiley, New York.

Johnston, M. and L. Wallace. 1990. Stress and medical procedures. Oxford University Press, Oxford, UK.

Kaplan, R. 2001. The nature of the view from home: Psychological benefits. Environ. Behav. 33(4):507-542.

Kaplan, R. and S. Kaplan. 1995. The experience of nature: A psychological perspective. Ulrich's, Ann Arbor, MI.

Laviana, J.E. 1985. Assessing the impact of plants in the simulated office environment: A human factors approach. Kansas State University, Manhattan, PhD Diss.

Laviana, J.E., R.H. Mattson, and F.H. Rohles. 1983. Plants as enhancers of the indoor environment. Proc. 27th Ann. Mtg. Human Factors Soc., Norfolk, VA. p. 738-741

Littell, R.C., G.A. Milliken, W.W. Stroup, and R.D. Wolfinger. 2006. SAS for mixed models. SAS Institute, Cary, NC.

Lohr, V.I. 1992. The contribution of interior plants to relative humidity in an office, p. 117-119. In: P.D. Relf (ed.). The role of horticulture in human wellbeing and social development. Timber Press, Portland, OR.

Lohr, V.I. and C.H. Pearson-Mims. 2000. Physical discomfort may be reduced in the presence of interior plants. HortTechnology 10(1):53-58

Lohr, V.I., C.H. Pearson-Mims, and G.K Goodwin. 1996. Interior plant may improve worker productivity and reduce stress in a windowless environment. J. Environ. Hort. 14(2):97-100.

Nishida, K., T. Kobashi, M. Osako, K. Shishida, T. Higuehi, and T. Higuchi. 1991. Studies on the elimination of gaseous pollutants by plants: Sorption model and diffusion co-efficients. Int. J. Environ. Stud. 42:17-26.

Park, S., R.H. Mattson, and E. Kim. 2004. Pain tolerance effects of ornamental plants in a simulated hospital patient room. Acta Hort. 639:241-247.

Rohles, F.H. and G.A. Milliken. 1981. A scaling procedure for environmental research. Proc. 25th Ann. Mtg. Human Factor Soc., Rochester, NY. p. 472-475.

Spielberger, C.D. 1983. Manual for the state-trait anxiety inventory (STAI) (Form Y: Self-evaluation questionnaire). Mind Garden, Redwood City, CA.

Tennessen, C.M. and B. Cimprich. 1995. Views to nature: Effects on attention. J. Environ. Psychol. 15:77-85.

Ulrich, R.S. 1979. Visual landscapes and psychological well-being. Landscape Res. $4: 17-23$.

Ulrich, R.S. 1981. Natural versus urban scenes: Some psycho-physiological effects. Environ. Behav. 13:523-556.

Ulrich, R.S. 1984. View through a window may influence recovery from surgery. Science 224:420-421.

Ulrich, R.S. 1992. How design impacts wellness. Healthc. Forum J. 35:20-25.

Ulrich, R.S. and R.F. Simons. 1986. Recovery from stress during exposure to everyday outdoor environments, p. 115122. In: J. Wineman, R. Barnes, and C. Zimring (eds.). The cost of not knowing. Proc. 27th Ann. Conf. Environ. Design Res. Assn. Washington, DC.

Ulrich, R.S., R.F. Simons, B.D. Losito, E. Fiorito, M.A. Miles, and M. Zelson. 1991. Stress recovery during exposure to natural and urban environment. J. Environ. Psychol. 11:201-230.

Verderber, S. and D. Reuman. 1987. Windows, views, and health status in hospital therapeutic environments. J. Architectural Planning Res. 4:120-133.

Wolverton, B.C. and J. Wolverton. 1993. Interior plants: Their influence on airborne microbes and relative humidity levels inside energy-efficient buildings. Res. Rpt. WES/100/05-93-011. Wolverton Environmental Service, Picayune, MS.

Wolverton, B.C., A. Johnson, and K. Bounds. 1989. Interior landscape plants for indoor air pollution abatement: Final report. Natl. Aeronautics Space Admin., John C. Stennis Space Center, MS.

Wood, R.A., R.L. Orwell, J. Tarran, F. Torpy, and M. Burchett. 2002. Potted plant/growth media interactions and capacities for removal of volatiles from indoor air. J. Hort. Sci. Biotechnol. 77(1):120-129. 